\title{
CYP7A1 genotypes and haplotypes associated with hypertension in an obese Han Chinese population
}

\author{
Lingyu Fu ${ }^{1,3}$, Yanyan Zhao ${ }^{2}$, Xiaomei Wu${ }^{1}$, Hong Liu ${ }^{2}$, Jingpu Shi ${ }^{1,3}$, Jingyu $\mathrm{Lu}^{2}$ and Bo Zhou ${ }^{1}$
}

This study investigated the association between single-nucleotide polymorphisms (SNPs; rs3808607 and rs1125226) within the CYP7A1 promoter and hypertension susceptibility in a Han Chinese population. From 2003 through 2006, a populationbased case-control study was performed in a cohort of 1187 randomly selected Han Chinese subjects. A sib-pair study for a transmission disequilibrium test analysis was carried out in 76 hypertensive (HT) families $(n=312)$ from northeastern Liaoning province. SNPs were detected using real-time PCR. No significant differences were found in the genotype or allele frequencies of either SNP $(P>0.05)$, with no excessive allele sharing. For rs3808607, the frequency of the AA genotype in obese hypertensive patients was $31.91 \%$, significantly higher than in normotensive (NT) subjects $(12.73 \%$; odds ratio $(0 R)=3.21$, $95 \%$ confidence interval $(\mathrm{CI}=1.35-7.66)$. For rs3808607, the AA genotype frequency was significantly higher in obese male HT subjects (27.87\%) than in matched NTs $(7.41 \%$; OR=4.83, 95\% Cl=1.03-22.65). After adjustment for environmental risk factors in obese participants, the AA genotype was associated with hypertension $(\mathrm{OR}=3.395,95 \% \mathrm{Cl}=1.412-8.162)$. Among subjects with body mass index $\geqslant 28 \mathrm{~kg} \mathrm{~m}^{-2}$, the HT and NT groups had significantly different frequencies of Hap I (C/C) and Hap IV (A/A). The frequencies of rs3808607 alleles in the CYP7A1 gene differed significantly between obese HT and NT men. Haplotypes I and IV were associated with hypertension in obese participants.

Hypertension Research (2011) 34, 722-727; doi:10.1038/hr.2011.18; published online 24 February 2011

Keywords: association; body mass index; cholesterol 7-hydroxylase promoter; haplotype; single-nucleotide polymorphism.

\section{INTRODUCTION}

The population of northeastern China has an age-standardized prevalence of hypertension of almost $35 \%$, which has made it an ideal region for the study of this disease. ${ }^{1}$ Several genetic cohort studies have been performed in this population, and associations have been reported between the likelihood of developing hypertension and single-nucleotide polymorphisms (SNPs) within CYP4F2 $(-421 \mathrm{G} / \mathrm{C})^{2}$ and NOS2 (-1026C/A). ${ }^{3}$ Hypertension mostly arises as a complex quantitative trait that is affected by varying combinations of genetic and environmental factors; the role of each gene is relatively minor, so many additional studies on susceptibility genes are required.

Hypertension rarely occurs in the absence of other metabolic disturbances. Dyslipidemia is one of the earliest and most frequent metabolic disturbances in hypertensive (HT) individuals, occurring concomitantly in over one-third of patients with hypertension. The liver has a central role in the regulation and maintenance of wholebody sterol balance. Conversion of cholesterol into bile acids in the liver, together with the secretion of cholesterol into bile, is the major quantitative pathway for eliminating cholesterol from the body. ${ }^{4}$ The initial stage of this process is catalyzed by the rate-limiting enzyme in the catabolism of cholesterol, cholesterol 7-hydroxylase (CYP7A1), ${ }^{4}$ which is a cytochrome P-450 enzyme. In the study by Toshio et al., ${ }^{5}$ the expression of CYP7A1 mRNA was decreased in spontaneously HT hyperlipidemic rats. Furthermore, in our study population, intake of animal oil and blood lipid metabolism disorders were independent risk factors for hypertension, according to the preliminary results of this study. Therefore, we selected CYP7A1 as a candidate gene for hypertension in our study population.

The CYP7A1 gene spans approximately $10 \mathrm{~kb}$ and contains six exons, five introns, one $5^{\prime}$-untranslated region and one $3^{\prime}$-untranslated region, and maps onto chromosome $8 \mathrm{q} 11 .{ }^{6}$ Several studies have been performed to assess the association of CYP7A1 with diseases related to lipid metabolism. Most studies concerning genetic variations in the CYP7A1 gene have focused on an $\mathrm{A} \rightarrow \mathrm{C}$ SNP in the promoter region, which is at position -278 from the translation initiation codon or position -204 from the transcriptional start site. The results appear to be conflicting as to whether this polymorphism is significantly associated with, for example, plasma lipid levels, ${ }^{7-9}$ risk of arteriosclerosis ${ }^{10}$ and gallstone disease ${ }^{11-13}$ in adults and children from Caucasian and Asian populations. Some intervention trials have suggested that the polymorphism has an important role in the metabolism of lipids. ${ }^{14,15}$

${ }^{1}$ Department of Clinical Epidemiology, The First Affiliated Hospital, China Medical University, Shenyang, China and ${ }^{2}$ Department of Medical Genetics, China Medical University, Shenyang, China

${ }^{3}$ These authors contributed equally to this work

Correspondence: Professor J Shi and Professor L Fu, Department of Clinical Epidemiology, The First Affiliated Hospital, China Medical University, No. 155, Nan Jing Bei Street, Shenyang, Liaoning Province 110001, China. 
The HapMap linkage disequilibrium patterns and haplotype structure can serve as a reference to select haplotype tagging SNPs (htSNPs) for association studies. Various degrees of linkage disequilibrium exist across different regions in different populations. As inferred from public HapMap data and analyzed by Nakamoto et al., ${ }^{16}$ rs3808607 (CYP7A1 -204C/A) and rs1125226 (CYP7A1 $-6791 \mathrm{C} / \mathrm{A})$ are likely to be the relevant htSNPs in the Han Chinese population in Beijing, China (CHB).

Therefore, rs3808607 and rs1125226 were selected in this study as tag variants to assess the genotypes of an extensive population in our study. To the best of our knowledge, no studies, including the genomewide association studies, have investigated whether these two polymorphisms are associated with the risk of hypertension. We aimed to identify hypertension risk haplotypes of the CYP7A1 regulatory region and estimate their impact on gene transcription, as well as their interaction with environmental factors.

\section{METHODS}

\section{Subjects}

From 2003 through 2006, a population-based case-control study was performed with 1187 subjects of Han Chinese origin, who were selected by random sampling in the northeastern region of Liaoning province, China. Additionally, a family-based study was conducted, consisting of 76 families with 312 members; each family had at least two offspring and one parent with hypertension. For all the individuals, blood pressure (BP) was measured three separate times on the right arm of seated subjects, with at least a 5-min rest between measurements; the individual average was calculated from these three measurements. Hypertension was defined as an average systolic $\mathrm{BP} \geqslant 140 \mathrm{~mm} \mathrm{Hg}$ and/or an average diastolic BP $\geqslant 90 \mathrm{~mm} \mathrm{Hg}$; subjects with diabetes mellitus, renal disease or secondary hypertension, as diagnosed by medical specialists, were excluded from the study. Normotension was defined as $\mathrm{BP}<140 / 90 \mathrm{~mm} \mathrm{Hg}$ with no history of cardiovascular disease. Trained research staff members administered a standardized questionnaire that recorded age, gender, smoking habits, alcohol consumption, and body height and weight measurements. All subjects underwent routine laboratory tests, including serum total cholesterol, triglyceride (TG), high-density lipoprotein cholesterol and low-density lipoprotein cholesterol. The characteristics of the subjects are listed in Table 1. Subgroups were divided according to their body mass index (BMI): ${ }^{17}$ low body weight, BMI $<18.5 \mathrm{~kg} \mathrm{~m}^{-2}$; normal body weight, BMI $18.5-23.9 \mathrm{~kg} \mathrm{~m}^{-2}$; overweight, BMI 24.0 $27.9 \mathrm{~kg} \mathrm{~m}^{-2}$; obese, $\mathrm{BMI} \geqslant 28 \mathrm{~kg} \mathrm{~m}^{-2}$. Ethical approval and informed consent were obtained from the local ethics committee and from all subjects prior to their inclusion into the study.

\section{Genotyping of CYP7A1}

DNA was isolated from whole blood with the use of FlexiGene DNA Kits (QIAgen, Hilden, Germany). The patients and the controls were genotyped for the rs3808607 and rs1125226 variants by a TaqMan Assay with a 7500 HT RealTime PCR System (Applied Biosystems, Foster City, CA, USA); all of the reagents and synthesized probes were purchased from Applied Biosystems (C_8893122_10 and C_27492121_20). Real-time PCR was performed using $12.5 \mu \mathrm{l}$ TaqMan $2 \times$ universal master mix, $0.625 \mu \mathrm{l}$ primer probe, $10.875 \mu \mathrm{l}$ DNase-free water and $1 \mu \mathrm{l}$ DNA sample, for a total volume of $25 \mu \mathrm{l}$ per single reaction in a 96-well plate. In each assay run, DNase-free water was used as a non-template control, and DNA of a known genotype was used as a positive control. Assay conditions were $2 \mathrm{~min}$ at $50^{\circ} \mathrm{C}, 10 \mathrm{~min}$ at $95^{\circ} \mathrm{C}, 40$ cycles of $92^{\circ} \mathrm{C}$ for $15 \mathrm{~s}$ and $60^{\circ} \mathrm{C}$ for $1 \mathrm{~min}$. The post-assay analysis was performed using SDS software (Applied Biosystems). The samples of genotyped CC, AA and CA were selected randomly and confirmed by sequencing (3100 Genetic Analyzer, Applied Biosystems).

\section{Statistical analyses}

Data were analyzed by SPSS, version 13.0, for Windows (SPSS, Chicago, IL, USA). The Hardy-Weinberg equilibrium was assessed with the use of $\chi^{2}$-tests. The differences in clinical characteristics between HTs and normotensives (NTs) were assessed by a two-sample $t$-test for quantitative variables and a $\chi^{2}$-test for categorical variables. Allele and genotype frequencies between the HT and normotensive (NT) groups were compared using the $\chi^{2}$-test. Multivariate logistic regression analyses were used to assess the relationship between each polymorphism and hypertension while considering the effects of other predictor variables. The probability for stepwise entry was 0.05 and the probability for stepwise removal was 0.1 . ORs and $95 \%$ confidence intervals (CIs) were computed from the aforementioned regression parameters. Adjusted ORs with 95\% CIs from the logistic regression analyses were used to estimate the relative risk of hypertension associated with genotype. To determine the effect of rs3808607 on BP variation in obesity, each genotype was assessed with oneway analysis of variance and least significant difference (LSD) analysis A linkage analysis in pedigrees was performed with the TDT-sTDT (transmission

Table 1 Demographic parameters for HT and NT individuals in the case-control and family-based studies

\begin{tabular}{|c|c|c|c|c|}
\hline \multirow[b]{2}{*}{ Parameter } & \multicolumn{2}{|c|}{ Case-control study } & \multicolumn{2}{|c|}{ Family-based study } \\
\hline & Hypertensive $(n=597)$ & Normotensive $(\mathrm{n}=590)$ & Hypertensive $(\mathrm{n}=261)$ & Normotensive $(\mathrm{n}=51)$ \\
\hline Sex (male/female) & $265 / 332$ & $230 / 360$ & $138 / 123$ & $19 / 32 *$ \\
\hline Age (years) & $49.16 \pm 7.51$ & $48.25 \pm 7.83^{*}$ & $50.70 \pm 16.50$ & $44.61 \pm 18.04^{*}$ \\
\hline Smoking (never/current) & $367 / 230$ & $384 / 206$ & $141 / 120$ & $35 / 16$ \\
\hline Drinking (never/current) & $379 / 218$ & $429 / 161^{*}$ & $162 / 99$ & $41 / 10^{*}$ \\
\hline Average SBP (mm Hg) & $160.80 \pm 20.31$ & $115.57 \pm 10.12^{*}$ & $161.93 \pm 32.04$ & $114.64 \pm 34.96 *$ \\
\hline Average DBP $(\mathrm{mm} \mathrm{Hg})$ & $101.40 \pm 11.55$ & $75.65 \pm 6.99 *$ & $97.44 \pm 24.67$ & $73.55 \pm 22.40 *$ \\
\hline $\mathrm{BMI}\left(\mathrm{kg} \mathrm{m}^{-2}\right)$ & $25.51 \pm 3.54$ & $23.47 \pm 3.57^{*}$ & $25.29 \pm 4.02$ & $25.10 \pm 4.57$ \\
\hline $\mathrm{TC}\left(\mathrm{mmol} \mathrm{I}^{-1}\right)$ & $4.97 \pm 1.29$ & $4.73 \pm 1.13^{*}$ & $5.00 \pm 1.69$ & $4.27 \pm 1.79 *$ \\
\hline $\mathrm{TG}\left(\mathrm{mmol} \mathrm{I}^{-1}\right)$ & $1.91 \pm 1.86$ & $1.45 \pm 1.80 *$ & $1.78 \pm 1.48$ & $1.23 \pm 1.01^{*}$ \\
\hline $\mathrm{HDL}\left(\mathrm{mmol} \mathrm{I}^{-1}\right)$ & $1.42 \pm 0.42$ & $1.52 \pm 0.48^{*}$ & $1.38 \pm 0.57$ & $1.28 \pm 0.57$ \\
\hline LDL (mmol I-1) & $2.79 \pm 0.91$ & $2.63 \pm 0.79 *$ & $2.62 \pm 1.00$ & $2.24 \pm 1.00 *$ \\
\hline Serum $\mathrm{Na}^{+}\left(\mathrm{mmol} \mathrm{I}^{-1}\right)$ & $142.19 \pm 4.53$ & $141.39 \pm 5.00$ & $139.82 \pm 5.64$ & $138.55 \pm 3.84$ \\
\hline Serum $\mathrm{K}^{+}\left(\mathrm{mmol} \mathrm{I}^{-1}\right)$ & $4.15 \pm 0.41$ & $4.20 \pm 0.39$ & $4.17 \pm 0.48$ & $4.17 \pm 0.47$ \\
\hline
\end{tabular}

Abbreviations: BMI, body mass index; DBP, diastolic blood pressure; HDL, high-density lipoprotein; HT, hypertensive; LDL, low-density lipoprotein; NT, normotensive; SBP, systolic blood pressure; TC, total cholesterol; TG, triglyceride.

${ }^{*} P<0.05$. 
disequilibrium test-sib transmission disequilibrium test) program v1.0, ${ }^{18}$ and the haplotype analysis was performed with the Phase program v2.0 (Matthew Stephens, Chicago, IL, USA). ${ }^{19}$

\section{RESULTS}

Individual characteristics

In the population-based study, as shown in Table 1, age and alcohol drinking were significantly different between HT and NT individuals $(P=0.042$ and 0.001 , respectively). In the population-based study, high-density lipoprotein and serum $\mathrm{Na}^{+}$were lower, and BMI, total cholesterol, TG and low-density lipoprotein were higher among the HT individuals than the corresponding NT individuals. As expected, systolic BP and diastolic BP were both significantly higher in HT than in NT $(P<0.0001$ for both). Similar results were also found in the family-based study, which indicated that male gender, smoking and higher total cholesterol, TG and low-density lipoprotein, but not higher BMI or lower high-density lipoprotein, were risk factors for hypertension.

Association of CYP7A1 SNPs with hypertension in the populationbased and family-based case-control studies

Genotype distributions and allele frequencies for the two SNPs tested are shown in Table 2. The genotype frequencies in both studies were in Hardy-Weinberg equilibrium $(P>0.05)$. There were no significant differences in the distributions of rs3808607 or rs1125226 genotypes or alleles between HT and NT subjects in either the population-based or family-based study. In the population-based study, the minor allele was C for rs 3808607 (frequency: $45.2 \%$ in the NTs; $46.6 \%$ in the HTs); for rs1125226, the minor allele was A (frequency: $39.2 \%$ in the NTs; $37.4 \%$ in the HTs). A similar result was found in the family-based study.

Unifactorial analyses showed that there were significant differences in BMI in the population-based study between the HTs and NTs (Table 1). Therefore, the data were analyzed in a stratified manner according to BMI. There were no significant differences found in this analysis for rs1125226. However, for rs3808607 (Table 3), the frequency of genotype AA in HT subjects $(31.91 \%)$ was significantly higher than that in NTs $(12.73 \%$; odds ratio $(\mathrm{OR})=3.21,95 \%$ $\mathrm{CI}=1.35-7.66)$ in the obese group. In the obese group, a further stratification analysis with regard to sex indicated that the frequency of genotype AA in male HT subjects $(27.87 \%)$ was significantly higher than the frequency in male NTs $(7.41 \%$; OR $=4.83,95 \% \mathrm{CI}=1.03-$ $22.65)$. In the obese group, based on the non-conditional logistic regression model, the AA genotype of rs3808607 was a significant risk predictor for hypertension $(\mathrm{OR}=3.395,95 \% \quad \mathrm{CI}=1.412-8.162$, $P=0.006$ ), after adjusting for those hypertension risk factors, such as age and gender, that were significantly different between the two groups (Table 1). The rs1125226 variant data were forced into the model but ultimately had to be excluded from it. Meanwhile, a higher TG level $(\mathrm{OR}=1.217,95 \% \mathrm{CI}=0.997-1.486, P=0.054)$ was also an independent risk predictor (Table 4).

Subsequently, data were analyzed to determine the effect of rs3808607 on BP variation in obesity (Table 5). In all of the obese subjects, homozygous AA carriers had significantly higher systolic BP and diastolic BP values than heterozygous and homozygous CC carriers. However, for all other parameters, there were no significant differences among homozygous AA, CC and heterozygous carriers.

A TDT-sTDT analysis was performed in the HT pedigree. For rs3808607, the $\chi^{2}$-score of transmission disequilibrium test (TDT) and the $Z$-score of sTDT were 1.485 and 0.357 , respectively $(P>0.05)$, and the combined $Z$-score was $0.589(P>0.05)$. For rs1125226, the $\chi^{2}$-score of TDT and the $Z$-score of sTDT were 0.021 and -0.165 , respectively $(P>0.05)$, and the combined $Z$-score was -0.052 $(P>0.05)$. These results show that no genotype for either SNP was transmitted preferentially within a pedigree $(P>0.05)$.

Haplotype analysis to assess their association with hypertension To investigate the individual and combined effects of the interactions of haplotypes in hypertension, the haplotypes were constructed according to the two SNPs arranged in the order of the rs3808607 and rs1125226 variants. After analysis by Phase software, four types of haplotypes were possible in our study population: Hap I (C/C), Hap II (A/C), Hap III (C/A) and Hap IV (A/A), with frequencies of 0.428 , $0.190,0.031$ and 0.351 , respectively. After $\chi^{2}$-analysis, there were no significant differences between the HT group and NT group with regard to the frequency of any of the four haplotypes. After stratified analysis in terms of BMI, there were significant differences between the HT group and NT group for Hap I and Hap IV when the BMI of the subject was greater than 28 (see Table 6; only the obese group is shown

Table 2 Genotype distributions and allele frequencies of two SNPs in the population-based and family-based case-control studies

\begin{tabular}{|c|c|c|c|c|c|c|c|c|}
\hline \multirow[b]{2}{*}{ SNP } & \multirow[b]{2}{*}{ Group } & \multicolumn{4}{|c|}{ Genotype } & \multicolumn{3}{|c|}{ Allele } \\
\hline & & $W T$ & $H t+M T$ & $\chi^{2}$ & $\mathrm{P}$ & Major/minor & $\chi^{2}$ & $\mathrm{P}$ \\
\hline \multicolumn{9}{|c|}{ Population based } \\
\hline \multirow[t]{3}{*}{ rs3808607 } & & $\mathrm{AA}$ & $\mathrm{CA}+\mathrm{CC}$ & & & $A / C$ & & \\
\hline & $\mathrm{HT}(n=597)$ & 167(0.280) & $303+127(0.720)$ & 0.33 & 0.56 & $0.534 / 0.466$ & 0.52 & 0.47 \\
\hline & NT $(n=590)$ & $174(0.295)$ & $299+117(0.705)$ & - & - & $0.548 / 0.452$ & - & - \\
\hline \multirow[t]{3}{*}{ rs1125226 } & & $\mathrm{CC}$ & $\mathrm{AC}+\mathrm{AA}$ & & & $\mathrm{C} / \mathrm{A}$ & & \\
\hline & $\mathrm{HT}(n=597)$ & $240(0.402)$ & $268+89(0.598)$ & 1.775 & 0.183 & $0.626 / 0.374$ & 0.813 & 0.367 \\
\hline & NT $(n=590)$ & 215(0.364) & $288+87(0.636)$ & - & - & $0.608 / 0.392$ & - & - \\
\hline \multicolumn{9}{|l|}{ Family based } \\
\hline \multirow[t]{3}{*}{ rs3808607 } & & $\mathrm{AA}$ & $\mathrm{CA}+\mathrm{CC}$ & & & $A / C$ & & \\
\hline & $\mathrm{HT}(n=261)$ & $83(0.318)$ & $130+48(0.682)$ & 1.69 & 0.19 & $0.569 / 0.431$ & 0.89 & 0.34 \\
\hline & NT $(n=51)$ & $21(0.412)$ & $21+9(0.588)$ & - & - & $0.618 / 0.382$ & - & - \\
\hline \multirow[t]{3}{*}{ rs1 125226} & & $\mathrm{CC}$ & $\mathrm{AC}+\mathrm{AA}$ & & & $\mathrm{C} / \mathrm{A}$ & & \\
\hline & $\mathrm{HT}(n=261)$ & $96(0.368)$ & $124+41(0.632)$ & 2.39 & 0.12 & $0.605 / 0.394$ & 2.60 & 0.11 \\
\hline & NT $(n=51)$ & $13(0.255)$ & $27+11(0.745)$ & - & - & $0.520 / 0.480$ & - & - \\
\hline
\end{tabular}

Abbreviations: HT, hypertensive; NT, normotensive; SNP, single-nucleotide polymorphism. 
Table 3 The stratified analysis by BMI and sex in population-based study for the rs 3808607 variant

\begin{tabular}{|c|c|c|c|c|c|c|c|}
\hline & \multicolumn{4}{|c|}{ Genotype } & \multicolumn{3}{|c|}{ Allele } \\
\hline & $A A$ & $C A+C C$ & $\chi^{2}$ & $P$ & $A / C$ & $\chi^{2}$ & $P$ \\
\hline $\mathrm{HT}(n=8)$ & $3(0.375)$ & $5+0(0.625)$ & Fisher's & 0.67 & $0.688 / 0.313$ & 1.61 & 0.21 \\
\hline NT $(n=37)$ & $10(0.270)$ & $18+9(0.730)$ & - & - & $0.514 / 0.486$ & - & - \\
\hline NT $(n=311)$ & $109(0.350)$ & $152+50(0.650)$ & - & - & $0.595 / 0.405$ & - & - \\
\hline \multicolumn{8}{|l|}{ Overweight } \\
\hline HT $(n=252)$ & $61(0.242)$ & $130+61(0.758)$ & 0.06 & 0.80 & $0.500 / 0.500$ & 0.06 & 0.81 \\
\hline NT $(n=182)$ & $46(0.253)$ & $93+43(0.747)$ & - & - & $0.508 / 0.492$ & - & - \\
\hline \multicolumn{8}{|l|}{ Obesity } \\
\hline Male HT $(n=61)$ & $17(0.279)$ & $36+8(0.721)$ & 4.63 & 0.03 & $0.574 / 0.426$ & 4.15 & 0.04 \\
\hline Male NT $(n=27)$ & $2(0.074)$ & $18+7(0.926)$ & - & - & $0.407 / 0.593$ & - & - \\
\hline \multicolumn{8}{|c|}{ OR (AA/CC+CA)(95\%Cl) $4.83(1.03-22.65)$} \\
\hline Female HT $(n=80)$ & $28(0.350)$ & $34+18(0.650)$ & 2.87 & 0.09 & $0.563 / 0.438$ & 2.24 & 0.13 \\
\hline Female NT $(n=28)$ & $5(0.179)$ & $15+8(0.821)$ & - & - & $0.446 / 0.554$ & - & - \\
\hline
\end{tabular}

Abbreviations: BMI, body mass index; HT, hypertensive; NT, normotensive; OR, odds ratio.

Table 4 Logistic analysis for hypertension risk factors in obese individuals within the population-based study

\begin{tabular}{|c|c|c|c|c|c|c|c|c|}
\hline \multirow[b]{2}{*}{ Variables } & \multirow[b]{2}{*}{$\beta$} & \multirow[b]{2}{*}{ s.e. } & \multirow[b]{2}{*}{ Wald } & \multirow[b]{2}{*}{ d.f. } & \multirow[b]{2}{*}{ Sig. } & \multirow[b]{2}{*}{$\operatorname{Exp}(\beta)$} & \multicolumn{2}{|c|}{$95 \% \mathrm{Cl}$ for $\operatorname{Exp}(\beta)$} \\
\hline & & & & & & & Lower & Upper \\
\hline TG & 0.197 & 0.102 & 3.726 & 1 & 0.054 & 1.217 & 0.997 & 1.486 \\
\hline Gene $(\mathrm{AA} / \mathrm{CC}+\mathrm{CA})^{*}$ & 1.222 & 0.447 & 7.462 & 1 & 0.006 & 3.395 & 1.412 & 8.162 \\
\hline Constant & -0.974 & 0.600 & 2.635 & 1 & 0.105 & 0.377 & - & - \\
\hline
\end{tabular}

Abbreviations: d.f., degree of freedom; Sig., significance.

*Frequency of genotype CA+AA as a control.

Table 5 Effect of different genotypes of the CYP7a1 on blood pressure and some risk factors for hypertension in the obesity group

\begin{tabular}{|c|c|c|c|c|c|}
\hline & $A A^{*}(\mathrm{n}=52)$ & $C A^{*}(\mathrm{n}=103)$ & $C C^{*}(n=41)$ & $F$ & $P$ \\
\hline Average SBP $(\mathrm{mm} \mathrm{Hg})$ & $156.71 \pm 27.05$ & $147.18 \pm 26.57$ & $146.34 \pm 27.58$ & 2.53 & 0.08 \\
\hline Average DBP $(\mathrm{mm} \mathrm{Hg})^{\mathrm{a}}$ & $100.58 \pm 13.37$ & $94.00 \pm 15.92$ & $92.93 \pm 14.09$ & 4.15 & 0.02 \\
\hline $\mathrm{TG}\left(\mathrm{mmol} \mathrm{I}^{-1}\right)$ & $2.18 \pm 1.75$ & $2.66 \pm 2.61$ & $2.59 \pm 3.09$ & 0.66 & 0.52 \\
\hline $\mathrm{HDL}\left(\mathrm{mmol} \mathrm{I}{ }^{-1}\right)$ & $1.36 \pm 0.44$ & $1.27 \pm 0.27$ & $1.35 \pm 0.34$ & 1.55 & 0.21 \\
\hline LDL $\left(\mathrm{mmol}^{-1}\right)$ & $2.83 \pm 1.13$ & $2.87 \pm 0.71$ & $2.87 \pm 0.75$ & 0.04 & 0.96 \\
\hline Serum $\mathrm{Ca}^{2+}\left(\mathrm{mmol} \mathrm{I}^{-1}\right)$ & $2.30 \pm 0.53$ & $2.44 \pm 0.47$ & $2.53 \pm 0.42$ & 2.90 & 0.06 \\
\hline Serum $\mathrm{Na}^{+}\left(\mathrm{mmol} \mathrm{I}^{-1}\right)$ & $142.29 \pm 3.99$ & $141.40 \pm 4.24$ & $142.22 \pm 4.42$ & 0.92 & 0.40 \\
\hline Serum $\mathrm{K}^{+}\left(\mathrm{mmol}^{-1}\right)$ & $4.17 \pm 0.39$ & $4.24 \pm 0.36$ & $4.20 \pm 0.30$ & 0.69 & 0.51 \\
\hline
\end{tabular}

Abbreviations: DBP, diastolic blood pressure; HDL, high-density lipoprotein; LDL, low-density lipoprotein; SBP, systolic blood pressure; TC, total cholesterol; TG, triglyceride. aThere were significant differences between genotypes CC and AA, CA and AA when performing analysis via the LSD method.

*All the data in this table are mean \pm s.d. 
Table 6 The frequency distribution of the four possible haplotypes of CYP7A1 in HT and NT individuals

\begin{tabular}{|c|c|c|c|c|c|}
\hline & $\begin{array}{c}\text { Haplotype } \\
\text { rs3808607/rs1 } 125226\end{array}$ & $\begin{array}{c}H T \\
(2 \mathrm{n}=1194)\end{array}$ & $\begin{array}{c}N T \\
(2 \mathrm{n}=1180)\end{array}$ & Total & $\mathrm{P}$ \\
\hline Hapl & $\mathrm{C} / \mathrm{C}$ & 0.437 & 0.419 & 0.428 & 0.36 \\
\hline Hapll & $\mathrm{A} / \mathrm{C}$ & 0.189 & 0.190 & 0.190 & 0.97 \\
\hline HaplII & $\mathrm{C} / \mathrm{A}$ & 0.029 & 0.033 & 0.031 & 0.60 \\
\hline HapIV & $\mathrm{A} / \mathrm{A}$ & 0.344 & 0.358 & 0.351 & 0.49 \\
\hline Obesity & & $H T(2 n=282)$ & $N T(2 n=110)$ & & \\
\hline \multirow[t]{2}{*}{ Hapl } & $\mathrm{C} / \mathrm{C}$ & 0.411 & 0.555 & 0.452 & 0.01 \\
\hline & & \multicolumn{2}{|c|}{$\mathrm{OR}=0.561(0.360-0.876)$} & & \\
\hline Hapll & $\mathrm{A} / \mathrm{C}$ & 0.188 & 0.155 & 0.179 & 0.44 \\
\hline HaplII & $\mathrm{C} / \mathrm{A}$ & 0.021 & 0.018 & 0.020 & $1.00 *$ \\
\hline \multirow[t]{2}{*}{ HapIV } & $A / A$ & 0.379 & 0.273 & 0.349 & 0.047 \\
\hline & & \multicolumn{2}{|c|}{$\mathrm{OR}=1.631(1.005-2.646)$} & & \\
\hline
\end{tabular}

Abbreviations: HT, hypertensive; NT, normotensive; OR, odds ratio.

*Fisher's exact test.

because of the significant difference in this cohort), which suggests that the A allele of rs3808607 is an independent risk factor for hypertension in obesity.

\section{DISCUSSION}

Hypertension is usually accompanied by dyslipidemia, but a causal relationship between them has not been elucidated. The enzyme encoded by the CYP7A1 gene serves a vital role in the maintenance of cholesterol homeostasis. In the study by Cooper et al., ${ }^{20}$ deletion of the segment from -213 to -91 caused a $40 \%$ reduction in promoter activity, which suggests that a positive element was removed. The crucial location of this polymorphism indicates that $-204 \mathrm{~A} / \mathrm{C}$ might interact with these regulatory elements and can modulate the transcriptional activity of CYP7A1. We studied the rs3808607 (-204A/C) and rs1125226 (-6791C/A) SNPs in the CYP7A1 promoter and did not observe any significant differences to suggest an association between them and hypertension in either a general populationbased or family-based case-control study. Conflicting results exist from many studies with regard to $-204 \mathrm{~A} / \mathrm{C}$. The frequency of the alleles of this polymorphism may also differ between different subsets of ethnically related populations. In one of the study conducted in Chinese populations, the minor allele was A, with a frequency of approximately $17.8 \% ;{ }^{21}$ in another population, the minor allele was C, with a frequency of approximately $43.27 \%$; 11 these results are consistent with results from studies involving Caucasians. ${ }^{7}$ In our population, the minor allele was $\mathrm{C}$, with a frequency of $46.6 \%$, which is also consistent with previous results involving Caucasians.

In our study, after stratified analysis using BMI as a confounding factor, a significant association was observed between the $-204 \mathrm{~A} / \mathrm{C}$ SNP and hypertension in the obese group; the AA genotype was a risk factor for hypertension. Further stratified analysis with regard to sex showed that AA was still a risk factor for hypertension in obese men, but was not a risk factor in obese women. This result appears to be similar to that of Couture et al., ${ }^{7}$ who found a small but statistically significant association between the $-204 \mathrm{~A} / \mathrm{C}$ polymorphism and plasma low-density lipoprotein concentration in men, but not in women. This indicates that sex and excess body fat might be critical factors in the development of hypertension. Visceral obesity and insulin resistance have a key role in the etiology of hypertension. ${ }^{22}$ Excessive body fat might be detrimental not only because of the metabolic implications but also because adipose tissue seems to be active in the synthesis and release of cytokine-like molecules that may influence insulin action, endothelial function and inflammatory responses. $^{23}$

Our results show that the CYP7A1 -204A/C SNP was associated with hypertension in obese men, and that the CYP7A1 -204AA SNP could be an independent risk factor for hypertension in the presence of increased TG in obese subjects. It has been suggested that a number of regulatory elements responsive to effectors, such as insulin, glucocorticoids and thyroid hormone, reside within the region that spans from -764 to +46 of the human CYP7A1 promoter. ${ }^{18}$ Therefore, we hypothesized that this polymorphism might change the binding site of some regulatory elements that react to insulin or other hormones. However, in the study by Abrahamsson et al., ${ }^{24}$ which used transient transfection experiments, no evidence was found for any difference between the $-204 \mathrm{C}$ and $-204 \mathrm{~A}$ alleles. One possible explanation for this result is that these two alleles influence the activity of CYP7A1 in the presence of stimulation by hormones or inflammatory factors, but not in the resting physiological state. A second explanation proposed by Abrahamsson et al. is that the $-204 \mathrm{~A} / \mathrm{C}$ SNP is in linkage disequilibrium with an as yet unidentified, functional polymorphism in the CYP7A1 gene. Indeed, cholesterol and dietary fats modulate CYP7A1 activity and gene expression. ${ }^{25}$ However, the exact mechanism by which different fatty acids can modulate CYP7A1 gene expression and the activity of CYP7A1 remains to be elucidated.

Given the poor representation of single SNPs, especially for the CYP7A1 -204A/C site, haplotype analysis would be more stable and helpful for the association analysis. Recently, Nakamoto et al. ${ }^{16}$ investigated the haplotype structure of the CYP7A1 gene, which shows differences in linkage disequilibrium blocks and haplotype frequencies between subjects of different ethnic origin. On the basis of their results and our analysis by HapMap in CHB, the rs1125226 variant was selected as htSNP and was analyzed by haplotype analysis together with rs3808607. To our knowledge, this was the first time that rs1125226 has been genotyped for association and haplotype analysis for the relationship between CYP7A1 and any disease. The results suggest that Hap I and Hap IV were the most common haplotypes, and they were associated with hypertension in obese individuals; a combination of A/A alleles at both the rs3808607 and rs1125226 SNP sites was a risk factor for hypertension, which was consistent with the individual SNP analysis in our population-based case-control study. However, it is still unknown whether rs1125226 is a functional site or a marker, and additional studies are necessary to confirm this issue.

This study provides additional evidence that overweight and obesity are associated with an increasing risk of hypertension in the Han Chinese population. As body size is one of the few risk factors for chronic and complicated diseases, such as hypertension, which can be modified throughout life, health promotion programs should focus on helping individuals to avoid becoming overweight or obese to prevent chronic diseases in all countries, including China.

In summary, to the best of our knowledge, this is the first report of the association of CYP7A1 gene polymorphisms with the risk of hypertension. Although, no significant association was observed in the general population, there were significant differences between allele frequencies of CYP7A1 -204A/C in HT and NT subjects in obese males. Hap I and Hap IV were associated with hypertension in obese individuals. With rising levels of obesity worldwide, it is critical to consider the potentially deleterious impact of hypertension and dyslipidemia. Moreover, because of limited sample size in the obese population in our study and the hypothesis that the polymorphism 
might change the binding site of some regulatory elements that could respond to insulin or other hormones, studies that combine larger sample populations with basic functional biological experiments are necessary.

\section{CONFLICT OF INTEREST}

The authors declare no conflict of interest.

\section{ACKNOWLEDGEMENTS}

This work was supported by grants from Program of the National Natural Science Foundation of China (30800944 and 30671796).

1 Shi JP, Wang HL, Li H, Dong W, Fu LY, Qi GX, Jia ZM, Yang HY, Gong W, Kang H, Gao $X G$, Wang WL, Jiang YS, Li JG. The epidemiological survey of prevalence rate of hypertension in the countryside of Zhangwu county, Liaoning province. Zhonghua Liu Xing Bing Xue Za Zhi 2003; 24: 547-550.

2 Liu $\mathrm{H}$, Zhao $\mathrm{Y}$, Nie $\mathrm{D}$, Shi J, Fu L, Li Y, Yu D, Lu J. Association of a functional cytochrome P450 4F2 haplotype with urinary 20-HETE and hypertension. J Am Soc Nephro 2008; 19: 714-721.

3 Fu L, Zhao Y, Lu J, Shi J, Li C, Liu H, Li Y. Functional single nucleotide polymorphism$1026 \mathrm{C} / \mathrm{A}$ of inducible nitric oxide synthase gene with increased YY1-binding affinity is associated with hypertension in a Chinese Han population. J Hypertens 2009; 27 : 991-1000.

4 Luoma PV Cytochrome P450 and gene activation-from pharmacology to cholesterol elimination and regression of atherosclerosis. Eur J Clin Pharmacol 2008; 64: 841-850.

5 Kumai T, Oonuma S, Kitaoka Y, Tadokoro M, Kobayashi S. Biochemical and morphological characterization of spontaneously hypertensive hyperlipidaemic rats. Clin Exp Pharmacol Physiol 2003; 30: 537-544.

6 Nishimoto $M$, Noshiro M, Okuda K. Structure of the gene encoding human liver cholesterol 7 alpha-hydroxylase. Biochim Biophys Acta 1993; 1172: 147-150.

7 Couture P, Otvos JD, Cupples LA, Wilson PW, Schaefer EJ, Ordovas JM. Association of the A-204C polymorphism in the cholesterol 7alpha-hydroxylase gene with variations in plasma low density lipoprotein cholesterol levels in the Framingham Offspring Study. $J$ Lipid Res 1999; 40: 1883-1889.

8 Wang J, Freeman DJ, Grundy SM, Levine DM, Guerra R, Cohen JC. Linkage between cholesterol 7alpha-hydroxylase and high plasma low-density lipoprotein cholesterol concentrations. J Clin Inves 1998; 101: 1283-1291.

9 Hofman MK, Groenendijk M, Verkuijlen PJ, Jonkers IJ, Mohrschladt MF, Smelt AH, Princen HM. Modulating effect of the A-278C promoter polymorphism in the cholesterol 7alpha-hydroxylase gene on serum lipid levels in normolipidaemic and hypertriglyceridaemic individuals. Eur J Hum Gene 2004; 12: 935-941.
10 Poduri A, Khullar M, Bahl A, Sharma YP, Talwar KK. A combination of proatherogenic single-nucleotide polymorphisms is associated with increased risk of coronary artery disease and myocardial infarction in Asian Indians. DNA Cell Bio 2009; 28: 451-460.

11 Jiang ZY, Han TQ, Suo GJ, Feng DX, Chen S, Cai XX, Jiang ZH, Shang J, Zhang Y, Jiang $Y$, Zhang SD. Polymorphisms at cholesterol 7alpha-hydroxylase, apolipoproteins B and $\mathrm{E}$ and low density lipoprotein receptor genes in patients with gallbladder stone disease. World J Gastroenterol 2004; 10: 1508-1512.

12 Juzyszyn Z, Kurzawski M, Lener A, Modrzejewski A, Pawlik A, DroŸdzik M. Cholesterol 7alpha-hydrolase (CYP7A1) c.-278A $>C$ promoter polymorphism in gallstone disease patients. Genet Test 2008; 12: 97-100.

13 Srivastava A, Pandey SN, Choudhuri G, Mittal B. Role of genetic variant A-204C of cholesterol 7alpha-hydroxylase (CYP7A1) in susceptibility to gallbladder cancer. $\mathrm{Mol}$ Genet Metab 2008; 94: 83-89.

14 Kovár J, Suchánek P, Hubácek JA, Poledne R. The A-204C polymorphism in the cholesterol 7alpha-hydroxylase (CYP7A1) gene determines the cholesterolemia responsiveness to a high-fat diet. Physiol Res 2004; 53: 565-568.

15 Hofman MK, Weggemans RM, Zock PL, Schouten EG, Katan MB, Princen HM. CYP7A1 A-278C polymorphism affects the response of plasma lipids after dietary cholesterol or cafestol interventions in humans. J Nutr 2004; 134: 2200-2204.

16 Nakamoto K, Wang S, Jenison RD, Guo GL, Klaassen CD, Wan YJ, Zhong XB. Linkage disequilibrium blocks, haplotype structure, and htSNPs of human CYP7A1 gene. BMC Genet 2006; 7: 29

17 Zhou BF, Cooperative Meta-Analysis Group of the Working Group on Obesity in China. Predictive values of body mass index and waist circumference for risk factors of certain related diseases in Chinese adults-study on optimal cut-off points of body mass index and waist circumference in Chinese adults. Biomed Environ Sci 2002; 15: 83-96.

18 Spielman RS, Ewens WJ. A sibship test for linkage in the presence of association: the sib transmission/disequilibrium test. Am J Hum Genet 1998; 62: 450-458.

19 Stephens M, Smith NJ, Donnelly P. A new statistical method for haplotype reconstruction from population data. Am J Hum Genet 2001; 68: 978-989.

20 Cooper AD, Chen J, Botelho-Yetkinler MJ, Cao Y, Taniguchi T, Levy-Wilson B. Characterization of hepatic-specific regulatory elements in the promoter region of the human cholesterol 7alpha-hydroxylase gene. J Biol Chem 1997; 272: 3444-3452.

21 Zhou B, Zhang SZ, Xiao CY, Zhang KL, Zhang L, Li GX, Li P, Liu HK, Zheng KQ. Association of 7 alpha-hydroxylase gene polymorphism with levels of plasma lipids. $Y_{i}$ Chuan 2004; 26: 283-286.

22 Ferrannini E, Natali A, Capaldo B, Lehtovirta M, Jacob S, Yki-Järvinen H. Insulin resistance, hyperinsulinemia, and blood pressure: role of age and obesity. European Group for the Study of Insulin Resistance (EGIR). Hypertension 1997; 30: 1144-1149.

23 Yajnik CS. The lifecycle effects of nutrition and body size on adult adiposity, diabetes and cardiovascular disease. Obes Rev 2002; 3: 217-224.

24 Abrahamsson A, Krapivner S, Gustafsson U, Muhrbeck O, Eggertsen G, Johansson I, Persson I, Angelin B, Ingelman-Sundberg M, Björkhem I, Einarsson C, van't Hooft FM. Common polymorphisms in the CYP7A1 gene do not contribute to variation in rates of bile acid synthesis and plasma LDL cholesterol concentration. Atherosclerosis 2005; 182: 37-45.

25 Chiang JY. Regulation of bile acid synthesis. Front Biosci 1998; 3: d176-d193. 